\title{
Optimal fiscal decentralization: Redistribution and welfare implications
}

\author{
Erkmen Giray Aslim ${ }^{\mathrm{a}}$, Bilin Neyapti ${ }^{\mathrm{b}, *}$ \\ a Lehigh University, Department of Economics, Bethlehem, PA 18015, USA \\ b Bilkent University, Department of Economics, Bilkent, Ankara 06800, Turkey
}

\section{A R T I C L E I N F O}

\section{JEL codes:}

E62

H77

Keywords:

Fiscal decentralization

Welfare

Fiscal efficiency

Income distribution

\begin{abstract}
A B S T R A C T
The literature has been inconclusive regarding the welfare effects of fiscal decentralization (FD), defined here as the extent to which local governments collect and spend local tax revenues. We present an original model to investigate formally the distributional and welfare implications of FD. In contrast to the standard approach that compares the implications of full FD with that of centralization, we consider that the central government chooses the level of FD to maximize welfare in a heterogeneous country. Noncooperatively, local governments choose their tax collection effort to maximize local utility. We show that an increase in the tax rate leads optimal FD to increase so as to compensate for the welfare loss from decreasing optimal local tax effort. Hence, welfare and income distribution improve in FD at its intermediate, rather than extreme, levels. We coin this result as the decentralization-Laffer curve. As regional spillovers increase, FD is less desirable as it deteriorates welfare and income distribution. This finding provides a novel support for the decentralization theorem and contributes to the fiscal policy debate.
\end{abstract}

\section{Introduction}

Fiscal decentralization (FD), defined as the devolution of fiscal power and responsibilities to sub-national governmental units, has been argued to improve democratic governance practices and thus to contribute to economic efficiency. ${ }^{1}$ Heterogeneity in local preferences, combined with asymmetric or incomplete information, that put local fiscal activity in a favorable position constitute the main rationale of this argument. The main policy implication that follows is that decentralizing public good provision is welfare-enhancing especially when regions are heterogeneous and spillovers are small, which is coined by Oates (1972) as the decentralization theorem. Notwithstanding the considerable attention the literature has paid to the efficiency and welfare implications of FD, the findings are hitherto somewhat inconclusive. ${ }^{2}$ Investigating the optimal level of FD vis-à-vis its redistributive, as well as efficiency, implications seems essential for prudent fiscal policy design. This paper aims to contribute to the literature in this regard.

Recent studies debated the argument that FD is a mechanism of increasing efficiency in public good delivery, however, on the basis that local governments usually do not fully internalize the externalities of their actions and they face various forms of capacity constraints. ${ }^{3}$ To increase efficiency and welfare, it is therefore argued that FD has to be complemented by additional institutional mechanisms that ensure accountability and transparency of sub-national fiscal activity. Those mechanisms mainly entail improving governance and implementation of fiscal rules. ${ }^{4}$ Empirical findings also suggest that it is neither possible

\footnotetext{
* Corresponding author.

E-mail addresses: era314@lehigh.edu (E.G. Aslim), neyapti@bilkent.edu.tr (B. Neyapti).

${ }^{1}$ An inspection of the Fiscal Decentralization Indicators of the World Bank reveal the following stylized facts: i) federal systems generally have greater degrees of FD than the rest; ii)

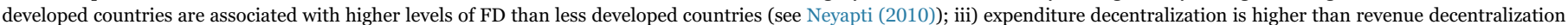
in both developed and developing countries; and iv) there are varying degrees of vertical and horizontal imbalances in each country.

${ }^{2}$ Following Tiebout's (1956) seminal work, there has been a growing literature on FD. See, for example, Oates (1972, 1998, 1999), Prud'homme (1995), and Diamond (1999) to name a few.

${ }^{3}$ See, for example, Prud'homme (1995), Stein (1998), Alesina et al. (1999), Rodden (2002), Tanzi (1994), and Fisman and Gatti (2000).

${ }^{4}$ See, for example, Burki et al. (1999), Tanzi (2000), De Mello and Barenstein (2001) and Neyapti (2010, 2013)), on the importance of various attributes of governance mechanisms

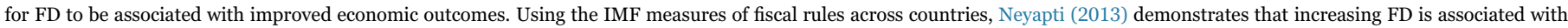

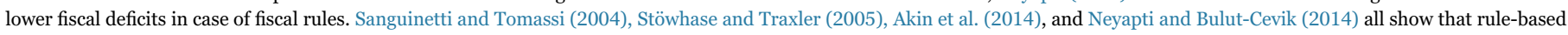
transfer mechanisms improve fiscal efficiency.
} 
nor desirable to decentralize public activity entirely; hence an intermediate level of FD is preferable for improving welfare or fiscal discipline. $^{5}$

The existing studies that formally model FD generally compare the outcomes of fully centralized and decentralized fiscal structures. Lockwood (2002), for example, investigates the effects of distributive policies in a political economy model with externalities, and argue that, in contrast with Oates (1972), weaker externalities may not increase the efficiency gains from decentralization, depending on the nature of heterogeneities. $^{6}$ Also in a political economy framework, Besley and Coate (2003) investigate the roles of spillovers and homogeneity for public good provision in cases of centralized and decentralized systems. They show that, due to cost sharing, decentralization may be superior to centralization even when spillovers are small and regions are homogeneous. Bellofatto and Besfamille (2015) compare the cases of partial and full decentralization with a focus on local fiscal and administrative capacity. Koethenbuerger (2008) investigates the welfare differentials of FD and centralization under spillovers and state the conditions that support the decentralization theorem. An important exception is Janeba and Wilson (2011) who state, also in a political economy model, that tax competition restricts the efficiency of decentralization, and show that an intermediate level of decentralization is optimal.

To our best knowledge, the literature has not yet provided a formal study of the welfare and redistributive implications of the optimal choice of the degree of FD in view of heterogeneous localities and spillover effects. The current study presents a framework where the extent to which the local revenue base is to be utilized locally is decided optimally by the central government, in a strategic interaction with local governments. It also investigates how structural and economic factors, specifically the prevailing tax rate and the share of the public sector vis-à-vis the private sector in the utility function affect optimal FD.

The model assumes three types of goods in each locality: local private good, local public good and pure public good. Assuming that the economy is closed, the central government $(\mathrm{G})$ maximizes social welfare by choosing the degree of FD, which is assumed to be uniform across localities. ${ }^{7}$ The model is solved as a non-cooperative game between local governments (LGs) and G, where a representative LG chooses its relative tax collection effort, which determines the level of local public good. Given the complexity of the set-up, output is assumed to be given exogenously and the model is static.

The solution of the model reveals that an increase in the tax rate leads to an increase in optimal FD, but a decrease in the optimal tax collection effort, as well as in the effective tax rate. Given the feasible range of parameter values, maximum values of welfare and tax revenue correspond to a medium range of optimal FD values. In addition, income distribution improves for the medium range of optimal FD values. Hence, the paper's findings caution the policy makers against a full-fledged and unconditional fiscal decentralization.

As an extension of the benchmark model, we investigate the optimal choice of FD when local public good provision has positive or negative spillover effects. The solution of the model reveals that spillovers have a

\footnotetext{
${ }^{5}$ See, for example, Neyapti (2010). The non-linear effects of FD are also demonstrated by Wang (2013) in the context of the FDI flows to China. While there are numerous studies on the macroeconomic effects of FD in China, Qichun (2014), for example, investigates the effects of FDI flows on FD in China and finds a positive association; Zhang and Zou (1998) demonstrate the negative effects of FD on growth in China. Mah (2013) observes that FD does not have a significant effect on income distribution. Gradstein (2016) explains the incentive for non-democratic governments to adopt fiscal decentralization, mainly to avoid the hold-up problem.

${ }^{6}$ Among the recent studies, Crivelli and Staal (2013), for example, investigate the bailout policy of the government vis-à-vis the optimal size of the local public good and conclude that the size of districts matter for the decision making. Hatfield (2015) demonstrates that tax policy is chosen optimally to promote growth under decentralization and not under decentralization.

${ }^{7}$ Oates (1972) refers to it as policy uniformity. See, also Cremer and Palfrey (1996).
}

positive effect on optimal FD and negative effect on tax collection effort, which appear to challenge the main argument of the decentralization theorem that state that spillovers reduce the welfare gains of FD. However, simulations also show that, when both income distribution and welfare effects are taken into account, lower rates of FD is preferable than in the case of no spillovers.

The structure of the rest of the paper is as follows. Section 2 describes the model as a strategic game between the central government and the local governments, Section 3 provides the comparative statics and simulation results, Section 4 extends the model to incorporate spillover effects, and Section 5 concludes.

\section{The model}

We consider a closed economy where the initial income of each region $\left(Y_{i}\right)$ is predetermined. We treat the private sector as a passive agent so as to focus on the interrelationship between the central and local governments. The level of spending in locality $i$, denoted by $\widetilde{Y}_{i}{ }^{8}$ is given by the sum of private $\left(C_{i}\right)$ and public spending that is composed of local and central government spending, denoted by $G_{i}{ }^{L}$ and $G_{i}{ }^{C}$, respectively. ${ }^{9}$ Because $G_{i}^{C}$ is pure public good, it can be written that $G^{C}=G_{i}^{C}$. The current framework is static; hence $C_{i}$ is equal to the after tax income as there is no capital accumulation:

$\tilde{Y}_{i}=C_{i}+G_{i}^{L}+G_{i}^{C}$

where

$C_{i}=\left(1-t_{i}\right) Y_{i} ; G_{i}^{L}=\phi a_{i} t Y_{i} ; \quad$ and $\quad G_{i}^{C}=(1-\phi) t \sum_{i} Y_{i}$

For the tractability of the model, we assume that the only tax base is income, from which both the local and the central governments collect taxes. $t_{i}$ is the tax rate faced by region $i(i=1, \ldots, \mathrm{n})$ and it is equal to the sum of taxes collected by the local and the central governments:

$t_{i}=\left[a_{i} t \phi+t(1-\phi)\right]$

where $a_{i}$ is the relative tax collection effort (or capacity) of LG vis-à-vis the central government in region $i . \phi$ is the level of fiscal decentralization $(\phi \in[0,1])$ that stands for the share of the local government in both total tax-revenue collection and public spending. ${ }^{10}$ The first component of $t_{i}, a_{i} \phi t$, is the portion of tax revenue that is collected by $\mathrm{LG}_{i}$ and constitutes the sole source of financing for local public spending $\left(G_{i}{ }^{L}\right)^{11}$; given $\phi, a_{i t}$ is the effective tax rate of $\mathrm{LG}_{i}$. The second component of $t_{i},(1-\phi) t$, the portion of local taxes that is collected by $\mathrm{G}$ and spent as $G^{C}$, is consumed in equal amounts by each locality. Hence, $G_{i}{ }^{C}$ stands for a positive transfer to region $i$ if $(1-\phi) t Y_{i}<G^{C} .{ }^{12}$ All variables are expressed in per capita terms. $t$ is the constant average income tax faced by a representative agent in each region, and is assumed to be given exogenously. ${ }^{13}$

The regions are assumed to be homogeneous in all respects other than their initial incomes, hence, the model focuses on a representative LG. There is no tax competition. We first solve for the benchmark case of $n=2$, where $\mathrm{G}$ and LGs act non-cooperatively to determine the optimal levels of $\phi$ and $a_{i}$, respectively, given $t$.

\footnotetext{
${ }^{8}$ Total spending $\left(\widetilde{Y}_{i}\right)$ differs from income $\left(Y_{i}\right)$ by the amount of (positive or negative) transfers made by the central government. However, for the whole economy, the government budget is in balance, hence: $\sum_{i} \widetilde{Y}_{i}=\sum_{i} Y_{i}$.

${ }^{9}$ One may consider $G_{i}{ }^{L}$ as the local public good.

${ }^{10}$ For simplicity, $\phi$ is assumed to be invariant across regions.

${ }^{11}$ One could model local spending to result from joint projects of the local and central governments. The large extent of nonlinearities already existing in the model, however, lead us to exclude this option for purposes of clarity in presentation.

12 Both regions receive positive transfers when $t>0$ and $Y_{i}>0$ for all $i$.

${ }^{13}$ No explicit solution can be found to the problem where $\mathrm{G}$ optimizes both $\phi$ and $t$ due to the highly non-linear constraints of the model. An optimal solution for both $\phi$ and $t$ can be found, however, under the leader-follower type game as the corner solution, where $\phi^{*} \cong 1 ; a_{i}^{*} \cong 0$; and $t^{*} \cong 0$. This solution, however, is not economically intuitive.
} 
Both players are best responding to each other by acting strategically and the joint solution of their best response functions yields the Nash equilibrium. This framework is similar to Cournot's duopoly model (see, for example, Daughety, 1989). The social planner's problem yields the same optimal results as in this solution procedure because of regional symmetry assumption. ${ }^{14}$

\subsection{The local governments' problem}

The representative local government chooses its tax collection effort in order to maximize the local utility that is composed of both private and public (central and local) spending in the region. Local consumers and LG do not distinguish between $G^{L}$ and $G^{C}$ and hence receive the same level of utility from both. ${ }^{15}$ The utility function is concave and assumed to take the following log-linear form:

$\max _{a_{i}} U_{i}=\alpha \ln C_{i}+\beta \ln G_{i}^{L}+\beta \ln G_{i}^{C}$.

The first order condition of the problem subject to the constraints given in Eqs. (1) and (2) yields:

$a_{i}=\left(\frac{\beta}{\alpha+\beta}\right) \frac{1-t+\phi t}{\phi t}$

\subsection{The central government's problem}

The government chooses $\phi$ in order to maximize the social welfare, which is the unweighted sum of local utilities:

$\max _{\phi} \sum_{i} U_{i}=\sum_{i}\left(\alpha \ln C_{i}+\beta \ln G_{i}^{L}+\beta \ln G_{i}^{C}\right)$.

Given the expressions in Eqs. (1) and (2), the problem yields the first order condition for $i=1,2$ :

$$
\begin{aligned}
& \alpha t\left(\frac{1-a_{1}}{\left(1-t \phi a_{1}\right)-t(1-\phi)}+\frac{1-a_{2}}{\left(1-t \phi a_{2}\right)-t(1-\phi)}\right) \\
& \quad+2 \beta\left(\frac{1}{\phi}-\frac{1}{1-\phi}\right)=0
\end{aligned}
$$

which, using symmetry, is equal to:

$2 \alpha t\left(\frac{1-a_{1}}{\left(1-t \phi a_{1}\right)-t(1-\phi)}\right)+2 \beta\left(\frac{1}{\phi}-\frac{1}{1-\phi}\right)=0$

Lemma 2.1. $L G$ 's best response function implies that $\phi$ and $a_{i}$ are strategic substitutes whereas for $G$ they are strategic complements.

Proof. We need to show that the derivative of $a_{i}$ with respect to $\phi$ is non-increasing in the LGs' problem, and the derivative of $\phi$ with respect to $a_{i}$ is non-decreasing in the $G^{\prime}$ s problem. In the LGs' problem, $\frac{\partial a_{i}}{\partial \phi}=\left(\frac{\beta}{\alpha+\beta}\right) \frac{(t-1)}{\phi^{2} t} \leq 0$ holds for $t \in[0,1]$. For the G's problem, applying the implicit function theorem to Eq. (8) yields: $\quad \frac{\partial \phi}{\partial a_{i}}=\frac{2 \alpha t^{2}\left(a_{i}-1\right)^{2}}{\left(\frac{2 \beta\left(2 \phi^{2}-2 \phi+1\right)}{\left.\alpha^{2}(1-\phi+a)-1\right)^{2}}\right)\left(t\left(1-\phi+a_{i} \phi\right)-1\right)^{2}}$, which is non-negative for $t, \phi \in[0,1]$.

Lemma 2.2. The joint solution of Eqs. (5) and (6) yields the optimal values for $\phi$ and a representative $a_{i}$ :

$\phi^{*}=\left(\frac{\alpha t-\beta+2 \beta t}{\alpha t+2 \beta t}\right)$ and $a_{i}^{*}=\frac{-\beta}{\beta-t(\alpha+2 \beta)}$

\footnotetext{
14 The solution is available from the authors upon request.

${ }^{15} \mathrm{We}$ assume that government spending in a given locality generates local public good, whose source does not matter; undirected transfer spending would justify this assumption.
}

\section{Proof. See Appendix A.}

For a given set of feasible values of $\{\alpha, \beta, t\}$, the above solutions yield single values for $\phi^{*}$ and $a_{i}^{*}$, which implies that the joint solution of the problem exists. In addition, the proof of Lemma 2.1 shows that the best response functions intersect at a single point, which ensures that the equilibrium is unique.

In a Stackelberg framework, where we model the relationship between $\mathrm{G}$ and $\mathrm{LG}$ sequentially, we let $\mathrm{G}$ to be the first mover and choose $\phi$ and LG to follow by choosing $a_{i}$. This setup yields the same optimal values as those found in Eq. (9). Hence, the first-mover advantage does not exist. ${ }^{16}$

Lemma 2.3. $\phi^{*}$ and $a_{i}^{*}$ are both feasible for $t>\left[\frac{1}{(\alpha / \beta)+2}\right]$.

Proof. For $a_{i}^{*} \geq 0$, the necessary condition is: $t>\left[\frac{\beta}{\alpha+2 \beta}\right]=\left[\frac{1}{(\alpha / \beta)+2}\right]$. For $\phi^{*} \in(0,1)$ the constraint is: $0<\beta<t(\alpha+2 \beta)$, which is the same condition for $a_{i}^{*} .^{17}$

This condition implies that as $(\alpha / \beta)$ increases, the minimum value of $t$ decreases to obtain the feasible range of the optimal values of the problem solution. To give a numerical example, the lower bound for $t$ is $0.3 \overline{3}$ for $\alpha=\beta=0.5$, and $0.2 \overline{3}$ for $\alpha=0.7$ and $\beta=0.3$, for the feasibility of the solution. In the extreme case of $\beta=0, a_{i}^{*}$ is zero and $\phi^{*}$ is one, which is the case of full decentralization, implying no tax collection and no spending by the government. In the opposite case, the condition that ensures optimality of $\phi$ is that it is equal to zero (or $\beta=t \alpha+2 t \beta$ ), which is also the condition for $a_{i}^{*}$ to go to infinity.

Proposition 2.1. The minimum tax rate for which the competitive (decentralized) solution obtains increases as the relative utility share of the government spending $(\beta / \alpha)$ increases.

An example to clarify the above observations can be given for the cases of France and the U.S.: expenditure decentralization is about 0.45 in the U.S., whereas it is about 0.20 in France. ${ }^{18}$ With the average tax rate (measured by the tax burden to GDP ratio) of 0.25 and the share of government spending of 0.39 , the U.S. does not appear to have an optimal level of $\phi$. The current level of $\phi$ in the U.S. would be consistent, ceteris paribus, with a higher average tax rate, which is about 0.52 according to Eq. (9). For the case of France, where the average tax rate is about 0.45 and the government spending is about $0.22, \phi^{*}$ is approximately 0.23 according to Eq. (9), which is very close to the actual rate of 0.20 . This framework therefore suggests the existing rate of $\phi$ in France is about the welfare maximizing rate.

\section{Comparative statics}

This section further examines the non-cooperative solution of the optimal decisions of LGs and G. Comparative statics reported below are based on the closed form solutions (see Appendix B):

$\partial \phi^{*} / \partial t>0 ; \partial \phi^{*} / \partial \alpha>0 ; \partial \phi^{*} / \partial \beta<0 ; \partial a_{i}^{*} / \partial t<0 ; \partial a_{i}^{*} / \partial \alpha<0 ; \partial a_{i}^{*} / \partial \beta>0$

The following explanations can be provided. First, the positive relationship of $\phi^{*}$ with $t^{19}$ arises because it is optimal for $\mathrm{G}$ to increase $\phi$ to compensate for the reduction in $a_{i}^{*}$ 's. LGs' optimal response to an increase in $t$ is to reduce $a_{i}$ 's so as to compensate for the utility loss from a decrease in the disposable income, which reduces the utility from private consumption. The positive association between $t$ and $\phi^{*}$ is consistent with the empirical evidence, for example, for the case of China (Qichun, 2014).

\footnotetext{
${ }^{16}$ The result is different, however, when we introduce spillovers.

17 This specification is defined to avoid corner solutions as it is discussed earlier.

18 The numbers are rounded up. FD indicators are obtained from the World Bank, and the tax burden to GDP ratio is obtained from the Economic Freedom Index of the Heritage Foundation.

${ }^{19}$ The positive response of $\phi^{*}$ is decreasing in $t$.
} 


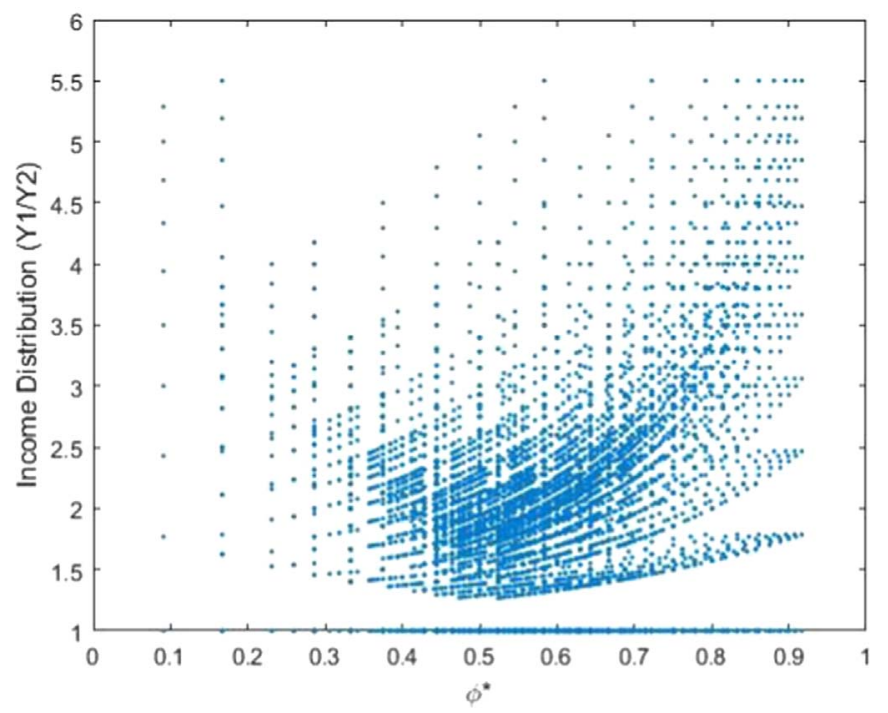

Fig. 1. Income distribution and fiscal decentralization.

Proposition 3.1. $\phi^{*}$ increases in $t$ and $a_{i}^{*}$ decreases in $t$.

Proposition 3.1 indicates that the effect of an increase in $t$ on local tax revenue can be ambiguous and a tax-Laffer curve may or may not exist. We investigate this issue with the help of simulations in the next section. ${ }^{20}$

The comparative statics also indicate that optimal $\phi$ is positively related with the share of the private sector $(\alpha)$. It is also observed that the sign of the relationships between $a_{i}^{*}$ and $\alpha$, and $a_{i}^{*}$ and $\beta$, are negative and positive, respectively. This is because increasing $a_{i}^{*}$ reduces disposable income, which reduces local utility more the higher the relative utility share of the private sector $(\alpha / \beta)$. Therefore, as $\alpha$ gets higher, LGs prefer to exert less effort to collect taxes.

Proposition 3.2. The higher is the ratio $(\alpha / \beta)$, the higher is $\phi^{*}$.

\subsection{Simulations and numerical examples}

In this section, we investigate the interactions of the optimal choices of $\left\{a_{i} ; \phi\right\}$ with the rest of the model variables $\left\{C_{i} ; G_{i}^{C} ; G_{i}^{L} ; a_{i} ; Y_{i} ; \widetilde{Y}_{i} ; U^{L G}\right.$ and $\left.U^{G}\right\}$ and the parameters $\{\alpha ; \beta$ and $t\}$, where $U^{L G}$ and $U^{G}$ denote the levels of utility pertaining to LG and G. We refer to $U^{G}$ as "welfare". Further, we investigate the relationship of $\left\{a_{i}^{*} ; \phi^{*}\right\}$ with income distribution $\left(Y_{1} / Y_{2}\right)$.

To obtain numerical solutions, we assign values to the model parameters as follows: $\{\alpha ; \beta ; t\} \in[0,1]$. We also fix one region's income and define the other region's income as a multiple $(x)$ of that, where $x$ varies over the range of $[1,10]$, which means that the income level in one region can be as small as one-tenth of the other region. Numerical simulations are performed covering all the feasible ranges of the underlying model parameters, where $a_{i}^{*} \in \mathbb{R}_{++} ; \phi^{*} \in[0,1]$; and $\left\{C_{i}\right.$, $\left.G_{i}{ }^{C}, G_{i}{ }^{L}, Y_{i}, \tilde{Y}_{i}\right\} \in \mathbb{R}_{+}$. The simulations generate 5,520 data points, an example of which is provided in Appendix C. Based on these, the following observations can be made:

i. Appendix C presents a numerical example of the simulation results. It demonstrates that income distribution improves as $\phi^{*}$ decreases, for a given $t$, corresponding to an increase in $\alpha$ (and a decrease in $\beta$ ). In response, income distribution $\left(Y_{1} / Y_{2}\right)$ takes the values of 1.53 and 1.40 , respectively, as opposed to the initial ratio of 2 . This reflects that the redistributive role of the $\mathrm{G}$ decreases with $\phi^{*} .{ }^{21}$ In

\footnotetext{
${ }^{20}$ This finding is consistent with the literature. See, for example, Adam et al. (2014) for the empirical analysis of the relationship between FD and the efficiency of public education and health spending in the OECD countries, where the authors show an inverted-U relationship.

${ }^{21}$ If $\phi^{*}=1$, no redistribution takes place and post income distribution is either 2 or 0.5 as reflected by the initial values of $Y_{1}$ and $Y_{2}$.
}

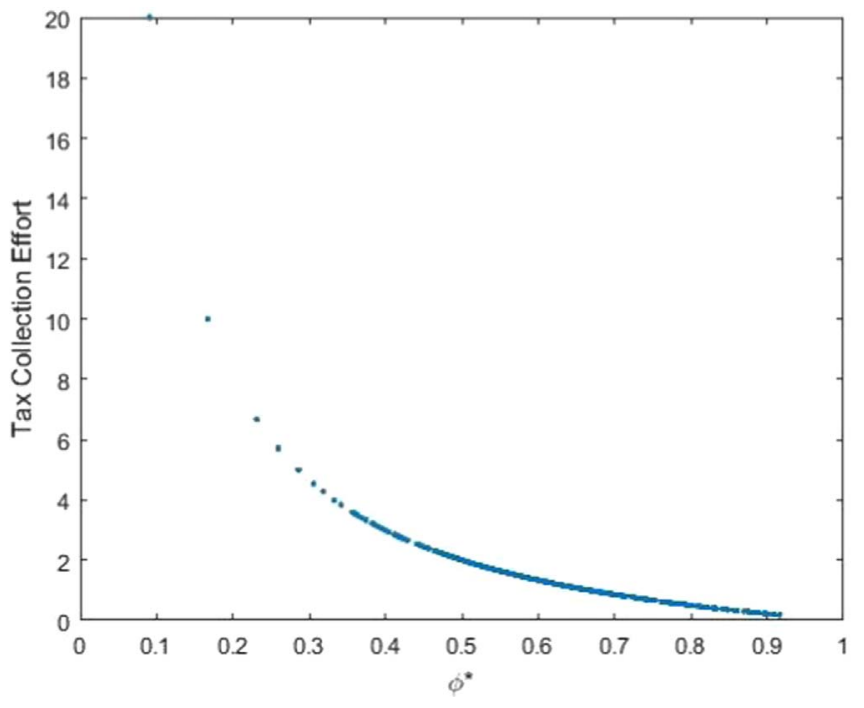

Fig. 2. Tax collection effort and fiscal decentralization.

addition, we observe that the effective tax rate increases in the relative utility share of the public sector $(\beta / \alpha) .^{22}$

This numerical example is only suggestive, however. A broader picture of the effects of $\phi^{*}$ can be seen based on the plots of the whole dataset generated by the simulations. Those plots are shown in Appendix D, which we turn to next.

ii. Fig. 1 shows that the possible range of income distribution, corresponding to the set of alternative parameter values, is most equitable in the case of $\phi^{*}=0.5$. The data plots on the horizontal axis correspond to the initial values of $Y_{1}=Y_{2}=10$, which implies no redistribution and hence $Y_{1} / Y_{2}$ remains as 1 for the whole range of $\phi^{*}$.

Fig. 2 shows that total tax collection effort is inversely related with $\phi^{*}$. This is consistent with the negative and positive definite comparative statics of $t$ with the former and the latter, respectively.

iv. Fig. 3 shows that the highest level of tax revenue is associated with an intermediate value of $\phi^{*}$. Because optimal tax effort declines in $\phi^{*}$ and $t$, the range of tax revenues shows a positive relationship with $\phi^{*}$ for $\phi^{*}<0.5$; and a negative one for $\phi^{*}>0.5$. This may be called as the decentralization-Laffer curve, which shows an inverted-U relationship between $\phi^{*}$ and tax revenues.

v. Accordingly, Fig. 4 shows that tax revenues first increase and then decrease in $a_{i}^{*}$. This is because $a_{i}^{*}$ falls in $t$, which in turn increases the tax revenue. However, we do not observe the falling portion of the tax-Laffer curve (see Fig. 5), which implies that the choice of $\phi^{*}$ is such that its rise in $t$ overcomes the negative effect of an increase in $t$ and $a_{i}^{*}$.

vi. Fig. 6 shows that welfare is also maximized for a medium range of optimal $\phi$ values. Specifically, the highest values of welfare is obtained for $0.4<\phi<0.7$.

vii. Based on Fig. 7, we observe that the range of welfare reaches its highest levels when income distribution is at reasonably equitable levels (specifically, for $Y_{1} / Y_{2}<2.5$ ). Similar to Fig. 1 , the values on the vertical axis correspond to the case of no redistribution.

These findings indicate, in a nutshell, that both welfare and income distribution reach their best points for a median range of $\phi^{*}$ values. This is consistent with the recent literature that argues that extreme

\footnotetext{
22 Under the assumption that the share of the private sector consumption in utility is 0.7 and that of the public sector is 0.3 , simulations for $\phi^{*}=0.5$ reveal that the effective tax rate faced by $\operatorname{LG}_{i}\left(a_{i} t\right)$ is 0.46 which is consistent with developed country average (see Appendix C). The de-facto effective tax rate $\left(a_{i} t \phi\right)$ is, on the other hand, 0.26.
} 


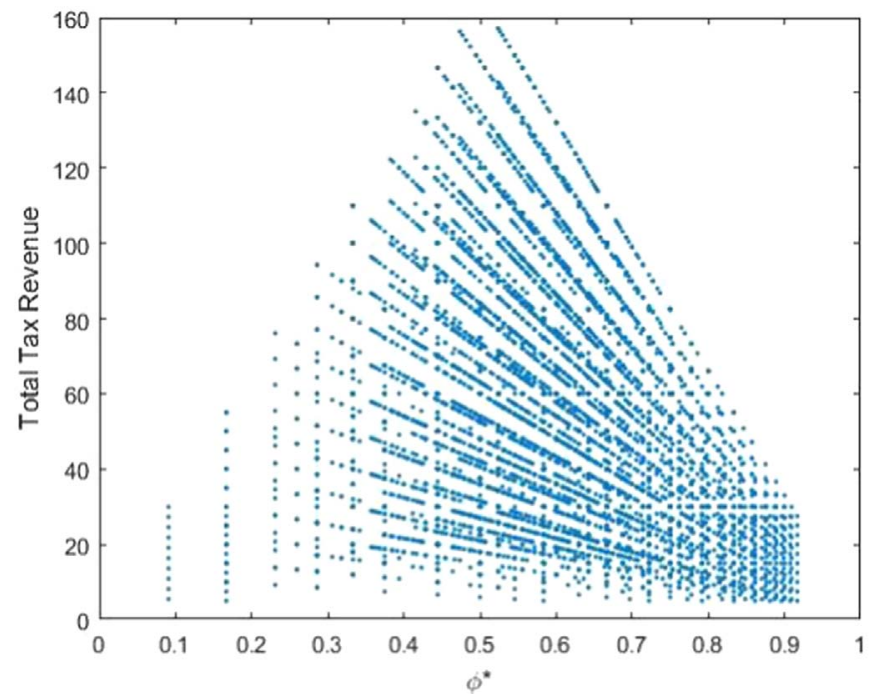

Fig. 3. Total tax revenue and fiscal decentralization.

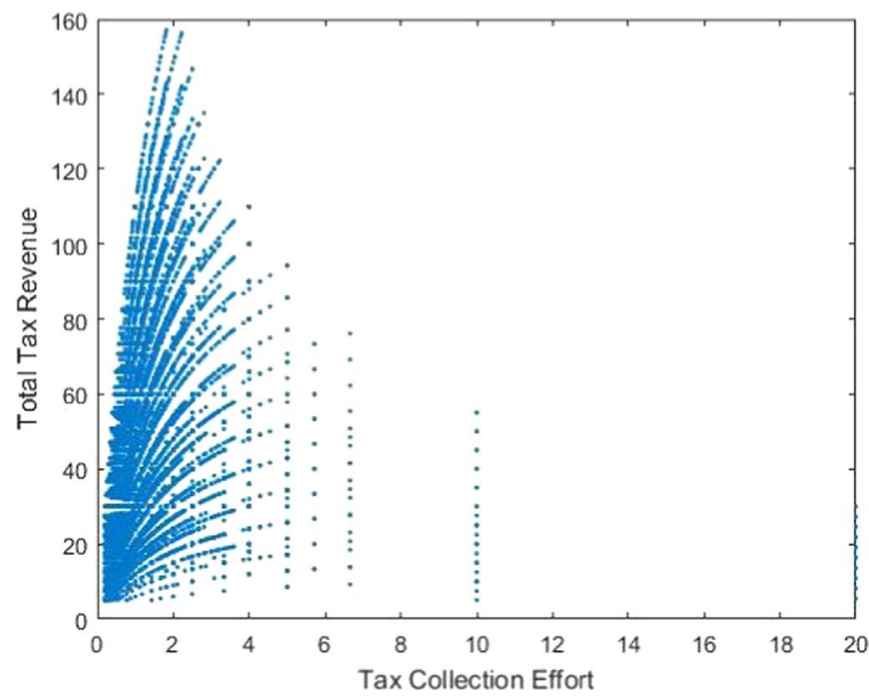

Fig. 4. Total tax revenue and tax collection effort.

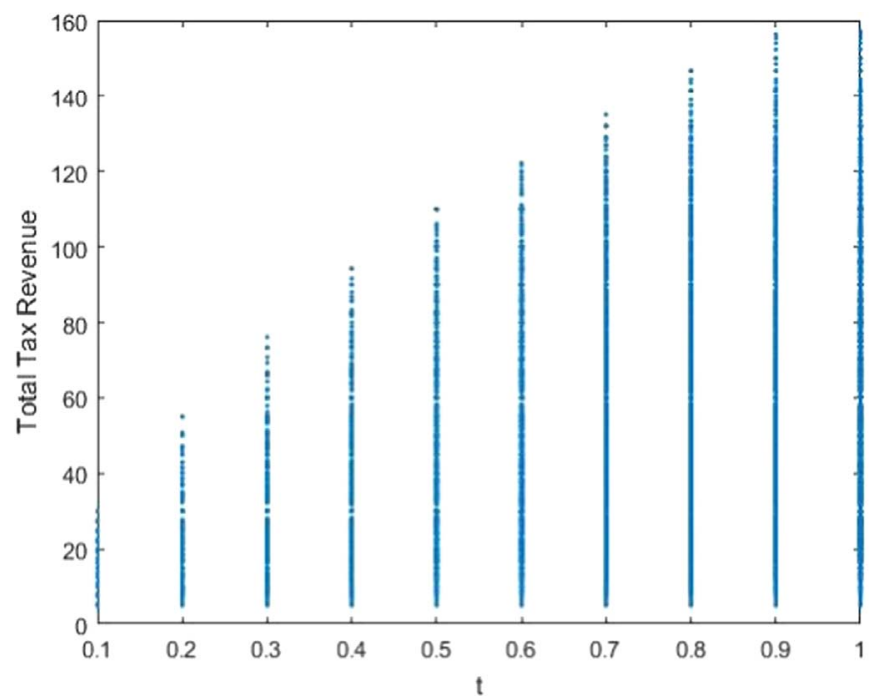

Fig. 5. Total tax revenue and tax rate.

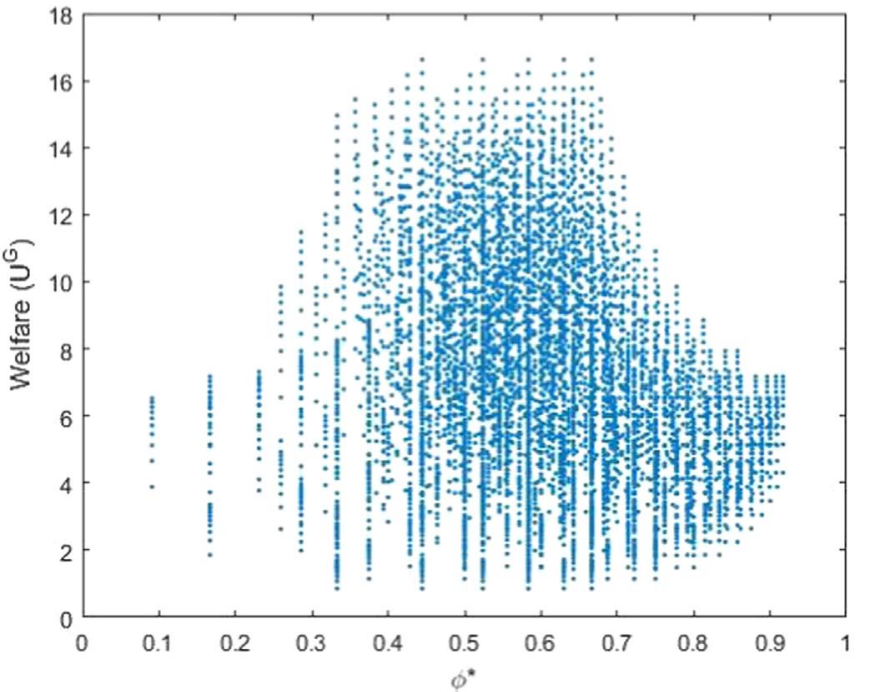

Fig. 6. Welfare and fiscal decentralization.

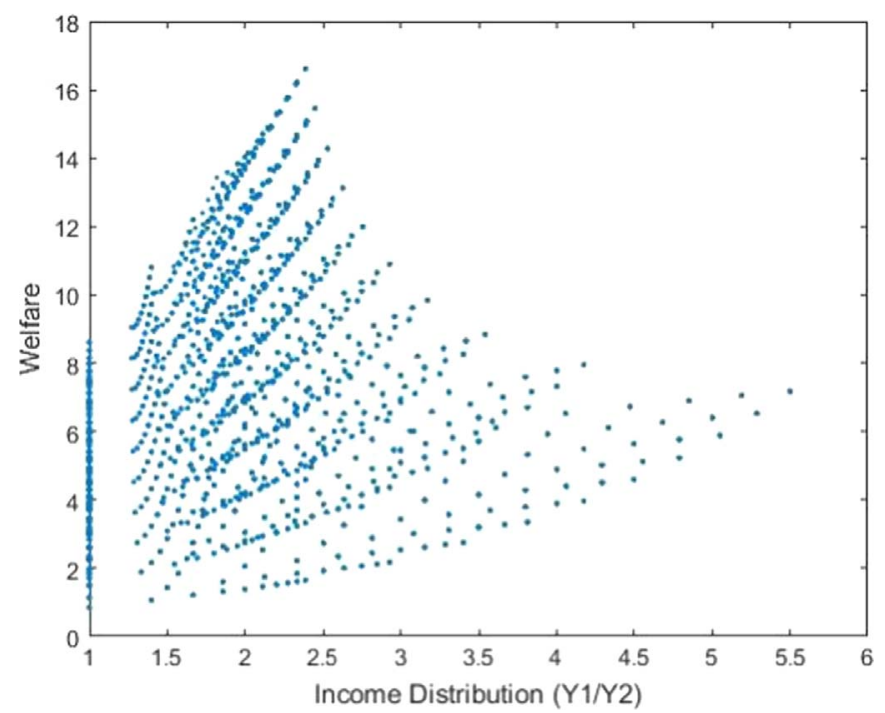

Fig. 7. Welfare and income distribution.

values of FD is not desirable for welfare and efficiency reasons (see, for example, Thiessen, 2003; Neyapti, 2010; Wang, 2013 among others). ${ }^{23}$

\section{Extension: spillover effects}

The benchmark model analyzed above allows for regional heterogeneity only in income levels. It is common, however, that local administrations take such actions that have effects on the welfare of other localities. These externaties may be in the form of influencing other localities' tax collection capacities and public spending needs. Positive spillovers may arise from infrastructure or education spending. An investment on a chemical plant, for example, may spillover negatively by polluting the environment and reducing tourism in a neighboring region, however. Tax exporting is another form of negative spillovers (see, for example, Boadway and Shah, 2009; Sorens, 2014).

In this section, we consider that local public spending may exert varying degrees of spillovers across the regions. According to Oates

\footnotetext{
${ }^{23}$ From a practical perspective, full FD is not optimal when fiscal institutions that ensure local tax collection efficiency are inadequate, resulting in a possible spiral of increasing tax rate and decreasing tax collection efficiency.
} 
(1972), spillovers may result in the underprovision of the local public goods and hence decentralization becomes less justified, a view that is challenged by Lockwood (2002) in a political economy context. In order to investigate how spillovers may alter the findings of our model, we modify the LGs' utility function as:

$\max _{a_{i}} U_{i, \text { spillover }}=\alpha \ln C_{i}+\beta\left(\ln G_{i}^{L}+s_{i} \ln G_{j}^{L}\right)+\beta \ln G_{i}^{C}$,

where $s_{i} \in[-1,1]$ stands for the degree of spillover of region $j$ 's public spending on region $i$. Two cases may arise under this specification: under one, the information about spillovers is observed only by the locals, and not by G; this is the case of asymmetric information. In this case, we observe that the LGs' first order condition does not contain $s_{i}$ and thus is the same as the one reported in Eq. (9). Because the optimal solution for $\phi$ also remains the same as those reported above, the distributional and welfare effects also remain the same as under no spillover effects.

Under the alternative case, when $\mathrm{G}$ has the full information about the spillovers, the G's problem becomes:

$\max _{\phi} \sum_{i} U_{i, \text { spillover }}=\sum_{i}\left(\alpha \ln C_{i}+\beta\left(\ln G_{i}^{L}+s_{i} \ln G_{j}^{L}\right)+\beta \ln G_{i}^{C}\right)$.

We solve the problems given in Eqs. (11) and (12), subject to the constraints given in Eqs. (1) and (2), both as a simultaneous and sequential move games, which are reported in Sections 4.1 and 4.2.

\subsection{Simultaneous move game}

Under full information about local spillovers, the first order conditions of the non-cooperative solution to the above problem is given by:

$$
\begin{aligned}
\frac{\partial U_{i, \text { spillover }}}{\partial a_{i}} & =\frac{-\alpha \phi t}{1-t \phi a_{i}-(1-\phi) t}+\frac{\beta}{a_{i}}=0 \frac{\partial \sum_{i} U_{i, \text { spillover }}}{\partial \phi} \\
& =\frac{2 \alpha t\left(1-a_{i}\right)}{1-t \phi a_{i}-(1-\phi) t}+\frac{\beta\left(2+\sum_{i} s_{i}\right)}{\phi}-\frac{2 \beta}{1-\phi}=0
\end{aligned}
$$

The joint solution of these first order conditions yields two distinct roots for $\phi^{*}$ and $a_{i}^{*}$ that are too long to report here. ${ }^{24}$ The comparative statics of those solutions are also too long to report; hence the signs are obtained through numerical simulations that cover all feasible ranges of the parameter values, in addition to the assumption about the range of spillovers: $s_{i} \in[-1,1]$. Based on the simulations, we observe that the effects of spillovers on $\phi^{*}$ and $a_{i}^{*}$ are: $\partial \phi_{\text {spillover }}^{*} / \partial s_{i} \geq 0$ and $\partial a_{i, \text { spillover }}^{*} / \partial s_{i} \leq 0$. The non-zero values of the derivatives are observed to be very few, however, and are available mostly for negative spillovers $\left(s_{i} \in[-1,0]\right)$. Hence, we conclude that the derivatives are not welldefined in this scenario.

We next investigate the relationship of $\phi^{*}$ with welfare and income distribution under spillovers. The most striking result we observe is that decentralization-Laffer curve disappears in the case of spillovers; that is, the intermediate range of $\phi^{*}$ values do not correspond to the highest levels of tax revenue anymore. Accordingly, income distribution and FD relationship is almost reversed as compared to the benchmark case: income distribution worsens as $\phi^{*}$ gets close to 0.5 , from above and below that point; while it is observed to improve as $\phi^{*}$ decreases, reaching the most equitable levels at $\phi^{*} \cong 0.1$. By contrast, the highest attainable levels of welfare correspond to more extreme values of $\phi^{*}\left(\phi^{*} \cong 0.7\right)$ than the benchmark case. ${ }^{25}$ In view of these numerical simulation results, a benevolent government facing large

\footnotetext{
${ }^{24}$ The solution functions are available from the authors upon request. Of the two roots of optimal $\phi$, only the first yields data for the whole range of $\phi^{*}$; hence, the analysis is based on the first root only.

${ }^{25}$ For one of the roots, for which model produces feasible outcomes only for $\phi^{*}<0.5$, welfare is also observed to increase as $\phi^{*}$ gets smaller. Data and graphs are available upon request from the authors.
}

regional spillovers would have to consider the trade-off between welfare and income distribution: if equitable distribution of income is viewed more important than increasing welfare, a low level of FD would be optimal. This observation is consistent with the decentralization theorem. ${ }^{26}$

The numerical examples in Appendix E also show that increasing spillovers have a positive effect on $\phi^{*}$ (compare the first two columns of Appendix E, and the first column of Appendix E to that in Appendix C) and result in worse income distribution than the benchmark case reported in Appendix C. In addition, increasing spillovers is observed to lead to worse income distribution (compare 1.58 to 1.67 , or 1.50 to 1.62 in Appendix E).

\subsection{Sequential move game}

In an alternative scenario, where spillovers are common knowledge to both LG and G, G moves first and sets $\phi$ taking LG's reaction function into account. LG in turn, chooses $a_{i}$ by optimally by taking $\phi$ given. This scenario is plausible considering that $\phi$ can be treated as a predetermined institutional variable according to which LGs take their actions. The first order conditions of the LG and G problems of this scenario are:

$$
\begin{aligned}
\frac{\partial U_{i, \text { spillover }}}{\partial a_{i}} & =\frac{-\alpha \phi t}{1-t \phi a_{i}-(1-\phi) t}+\frac{\beta}{a_{i}}=0 \frac{\partial \sum_{i} U_{i, \text { spillover }}}{\partial \phi} \\
& =\frac{2 \alpha t}{\phi t-t+1}+\frac{2 \beta t}{\phi t-t+1}+\frac{2 \beta s_{i} t}{\phi t-t+1}-\frac{2 \beta}{1-\phi}=0
\end{aligned}
$$

Lemma 4.1. The joint solution of Equations in (14) yields the non-cooperative optimal values for $\phi$ and $a_{i}$ :

$\phi_{\text {spillover }}^{*}=\left(1-\frac{\beta}{t\left(\alpha+\beta\left(2+s_{i}\right)\right)}\right)$ and
$a_{i, \text { spillover }}^{*}=\frac{\beta\left(\alpha+\beta+\beta s_{i}\right)}{(\alpha+\beta)\left(\alpha t-\beta+2 \beta t+\beta t s_{i}\right)}$

Lemma 4.2. $\phi_{\text {spillover }}^{*}$ and $a_{i, \text { spillover }}^{*}$ are feasible $\left(0<\phi_{\text {spillover }}^{*}<1\right.$ and $0<a_{i, \text { spillover }}^{*}<$ 1) when $\beta>0 .{ }^{27}$

Comparative statics of the optimal solutions with respect to $\{t, \alpha, \beta\}$ yield the same results as those reported earlier for the benchmark case. The following results are additional ${ }^{28}$ :

$\frac{\partial \phi_{\text {spillover }}^{*}}{\partial s_{i}}>0$ and $\quad \frac{\partial a_{i, \text { spillover }}^{*}}{\partial s_{i}}<0$

which reveals a strictly positive relationship between $s_{i}$ and $\phi^{*}$, unlike the non-sequential game between G and LG under spillovers; that is, negative spillovers reduce $\phi^{*}$ and positive spillovers increase it definitively. ${ }^{29}$ These results are also observed to be much more robust than the former case because they are defined for the whole range of $s_{i}^{\prime}$ 's.

These findings appear to challenge the decentralization argument $a$ la Oates (1972): the presence of spillovers actually makes the case for decentralization stronger. The simulations show, however, that the range of $\phi^{*}$ values at which welfare reaches its maximum values are about the same as the case without spillovers: some intermediate range of the $\phi^{*}$ values (specifically, $0.4<\phi^{*}<0.7$ ), although the lower tail of $\phi^{*}$ is observed to be associated with higher levels of welfare than in the benchmark case (as in Section 4.1).

\footnotetext{
${ }^{26}$ Decentralization theorem suggests that centralization can be justified when local governments do not internalize the externalities or when there are large spillovers.

${ }^{27}$ For $\beta=0, \phi_{\text {spillover }}^{*}=1$ and $a_{i, \text { spillover }}^{*}=0$, which is not feasible as discussed earlier. 28 The proof is trivial.

29 This result is consistent with that of Koethenbuerger (2008) who shows that increasing spillovers reduces the welfare differences between FD and centralization.
} 
On the other hand, decentralization-Laffer curve disappears (as in Section 4.1): tax revenue increases as $\phi^{*}$ falls and income distribution improves as $\phi^{*}$ approaches to the value of 0.1 . The remainder of the observations, namely with regards to the tax-Laffer curve, depicted in Appendix D for the case of no spillovers remains virtually the same.

Hence, the simulation results appear to be at odds with the comparative statics result that shows $\phi^{*}$ to increase in spillovers. The lowest levels of $\phi^{*}$ are associated with the highest attainable levels of redistribution (tax revenue) under spillovers, in contrast with the case of no spillovers. The following explains why these findings are actually not contradictory. Spillovers affect local utility through $G_{i}^{L}$ 's that increase in both $\phi$ and $a_{i}$, which, however, are negatively related with each other. When spillovers increase, if $\phi^{*}$ was to increase and $a_{i}^{*}$ was to fall as much as in the benchmark case, utility from $G^{L}{ }_{i}$ 's would still rise due to spillovers. It is therefore possible that welfare reaches highest attainable levels at lower levels of $\phi^{*}$ than in the benchmark case. The intuition can be further explained in case of a decrease in spillovers: because $\mathrm{G}$ knows that $a_{i}^{*}$ will increase in response, $\phi^{*}$ falls by more than the benchmark case (so that $t_{i}$ in Eq. (3) falls) in order to eliminate the utility loss from a reduction in $C_{i}$.

The findings are therefore consistent with the comparative static result that seems to challenge the decentralization theorem: as spillovers rise, $\phi^{*}$ increases. However, since the welfare measure adopted here, which is the sum of local utilities, does not tell anything about the income distribution resulting from the model's solution, a sound policy recommendation calls for a careful interpretation of the above results, which is as follows. If a benevolent government that faces regional spillovers considers both the welfare and income distribution implications of its choice, it would choose a low level of $\phi$ because it achieves larger redistribution without compromising much the level of welfare. From that perspective, it is indeed optimal to choose lower $\phi$ for higher rates of spillovers.

\section{Conclusion}

This paper contributes to the literature of fiscal decentralization by presenting a formal model to analyze the macroeconomic implications of optimizing fiscal decentralization (FD). We consider a framework where local governments determine their effective tax rates by choosing the degree of their tax collection effort optimally while the central government chooses FD optimally. Our benchmark case is when both local and central governments form their optimal decisions simultaneously in a non-cooperative fashion; we then also investigate the case of a sequential move game. Simulations are performed to assess the welfare effects of these interactions with and without the effect of spillovers across the regions.

The main finding of the paper is that it is optimal to increase the rate of fiscal decentralization (FD) the higher the tax rate so as to maintain the welfare level, given that the optimal local tax collection effort $\left(a_{i}^{*}\right)$ decreases in the tax rate. Given the strategic complementarity between the optimal values of $\mathrm{FD}\left(\phi^{*}\right)$ and $a_{i}^{*}$, increasing $\phi^{*}$ first leads to an increase in the tax revenue and then decreases it. Simulations also show that optimum welfare reaches its highest values and income distribution becomes most equitable at some medium range of $\phi^{*}$. We call this decentralization-Laffer curve. This formal result makes a notable contribution to the recent decentralization literature stating that extreme values of FD may not be optimal. A tax-Laffer curve is not observed, however, since the optimal choices of the central and local governments avoid the realization of the falling portion of the curve.

Utilizing both non-sequential and leader-follower frameworks to solve the benchmark model in the case of spillovers, we observe that $\phi^{*}$ increases but $a_{i}^{*}$ decreases with spillovers, ceteris paribus. The extreme levels of $\phi^{*}$ are also associated with relatively low levels of welfare, as in the case of no spillovers, although the attainable range of welfare corresponding to lower levels of $\phi^{*}$ is relatively much higher than the benchmark case. In the presence of spillovers, revenue collection and income distribution improves uniformly as $\phi^{*}$ falls.

Taking stock, we conclude that when there are no spillovers, welfare and income distribution improves for a median range of values of fiscal decentralization. Extremely low and high values of FD lead to efficiency losses that results in low tax revenues to be utilized for redistributive purposes. In the presence of spillovers, however, the current framework reveals that low FD would be the preferred policy of a benevolent government if distribution of income matters as much as the level of aggregate welfare.

\section{Acknowledgments}

We thank the conference participants at EcoMod 2014 Meetings and the seminar participants at Bilkent University. We are also indebted to Cagri Saglam, Ernest Lai, James Dearden, two anonymous referees for their invaluable comments. In addition, we are grateful to the Editor of Economic Modelling for his valuable guidance and comments. All the remaining errors belong to the authors.

\section{Appendix A. Model solution}

I. Proof of LG's First Order Condition (FOC). Substituting Eqs. (1) and (2) into (4) converts the problem into an unconstrained optimization as denoted below.

$$
\max _{a_{i}} U_{i}=\alpha \ln \left(Y_{i}-\phi a_{i} t Y_{i}-(1-\phi) t Y_{i}\right)+\beta \ln \left(\phi a_{i} t Y_{i}\right)+\beta \ln \left(\left(\sum_{i=1}^{n}\left((1-\phi) t Y_{i}\right)\right)\right)
$$

from which the first order condition is obtained as:

$$
\begin{aligned}
\frac{\partial U_{i}}{\partial a_{i}} & =\frac{-\alpha \phi t Y_{i}}{Y_{i}-\phi a_{i} t Y_{i}-(1-\phi) t Y_{i}}+\frac{\beta \phi t Y_{i}}{\phi a_{i} t Y_{i}}=0 \\
a_{i} & =\frac{\alpha}{\beta}\left(\frac{Y_{i}-\phi a_{i} t Y_{i}-(1-\phi) t Y_{i}}{\phi t Y_{i}}\right)=\frac{\alpha}{\beta}\left(\frac{1}{\phi t}-a_{i}-\frac{1}{\phi}+1\right) \\
a_{i} & =\frac{\beta}{\alpha+\beta}\left(\frac{1}{\phi t}-\frac{1}{\phi}+1\right)
\end{aligned}
$$

For each jurisdiction $(i=1,2)$, we have the same tax effort $\left(a_{1}=a_{2}\right)$. 
II. Proof of the G's FOC. Substituting Eqs. (1) and (2) into (6) converts the model into an unconstrained optimization given by:

$\max _{\phi} \sum_{i=1}^{n} U_{i}=\alpha \sum_{i=1}^{n} \ln \left(Y_{i}-\phi a_{i} t Y_{i}-(1-\phi) t Y_{i}\right)+\beta \sum_{i=1}^{n} \ln \left(\phi a_{i} t Y_{i}\right)+\beta \sum_{i=1}^{n} \ln \left(\left(\sum_{i=1}^{n}(1-\phi) t Y_{i}\right)\right)$

whose first order condition is:

$\frac{\partial \sum_{i=1}^{n} U_{i}}{\partial \phi}=\alpha \sum_{i=1}^{n}\left(\frac{-a_{i} t Y_{i}+t Y_{i}}{Y_{i}-\phi a_{i} t Y_{i}-(1-\phi) t Y_{i}}\right)+\beta \sum_{i=1}^{n}\left(\frac{a_{i} t Y_{i}}{\phi a_{i} t Y_{i}}\right)+\beta \sum_{i=1}^{n}\left(\frac{-\left(\sum_{i=1}^{n} t Y_{i}\right)}{\left(\sum_{i=1}^{n}(1-\phi) t Y_{i}\right)}\right)$

which can be simplified as:

$\alpha \sum_{i=1}^{n}\left(\frac{t\left(1-a_{i}\right)}{1-\phi a_{i} t-(1-\phi) t}\right)+n \beta\left(\frac{1}{\phi}-\frac{1}{1-\phi}\right)=0$.

For two jurisdictions $(i=1,2)$, the solution is given by:

$\alpha\left(\frac{t\left(1-a_{1}\right)}{1-\phi a_{1} t-(1-\phi) t}+\frac{t\left(1-a_{2}\right)}{1-\phi a_{2} t-(1-\phi) t}\right)+2 \beta\left(\frac{1}{\phi}-\frac{1}{1-\phi}\right)=0$

This expression yields three roots for $\phi$; we only use this general solution for Lemma 2.1.

III. Proof of Lemma 2.2. Given two jurisdictions, substituting Eq. (5) in (8) yields:

$2 \alpha\left(\frac{\left(1-\frac{\beta\left(1-\frac{1}{\phi}+\frac{1}{\phi t}\right)}{\alpha+\beta}\right) t}{1-(1-\phi) t-\frac{\beta \phi\left(1-\frac{1}{\phi}+\frac{1}{\phi t}\right) t}{\alpha+\beta}}\right)+2 \beta\left(-\frac{1}{1-\phi}+\frac{1}{\phi}\right)=0$

which yields:

$\beta\left(\frac{1-2 \phi}{-\phi(\phi-1)}\right)+\frac{\alpha\left((\alpha+\beta)-\beta\left(1-\frac{1}{\phi}+\frac{1}{\phi t}\right)\right) t}{(\alpha+\beta)(\phi t-t+1)-\beta(\phi t-t+1)}=0$

which can be simplified as:

$\beta\left(\frac{1-2 \phi}{-\phi(\phi-1)}\right)+\frac{\beta t-\beta+\alpha \phi t}{\phi(\phi t-t+1)}=0$

which yields (where $0<\{\alpha, \beta, t, \phi\}<1$ ):

$\phi^{*}=\frac{-\beta+\alpha t+2 \beta t}{(\alpha+2 \beta) t}$ and $\quad(\alpha+2 \beta) t \neq 0 \quad$ and $\quad \beta(\alpha+\beta) \neq 0$.

In order to obtain the corresponding optimal tax effort $\left(a_{i}\right)$, we substitute this expression in Eq. (5):

$$
\begin{aligned}
a_{i}^{*} & =\frac{\beta}{\alpha+\beta}\left(\frac{1}{\left(\frac{-\beta+\alpha t+2 \beta t}{(\alpha+2 \beta) t}\right) t}-\frac{1}{\frac{-\beta+\alpha t+2 \beta \alpha}{(\alpha+2 \beta) t}}+1\right)=\frac{\beta}{\alpha+\beta}\left(\frac{\alpha+2 \beta}{-\beta+\alpha t+2 \beta t}-\frac{(\alpha+2 \beta) t}{-\beta+\alpha t+2 \beta t}+1\right) a_{i}^{*} \\
& =\frac{\beta}{\alpha+\beta}\left(\frac{\alpha+2 \beta-\alpha t-2 \beta t-\beta+\alpha t+2 \beta t}{-\beta+t(\alpha+2 \beta)}\right)
\end{aligned}
$$

Since efforts are the same for each locality,

$a_{1}^{*}=a_{2}^{*}=\frac{-\beta}{\beta-t(\alpha+2 \beta)}$ 
Appendix B. Comparative static analysis

$\begin{aligned} \frac{\partial \phi^{*}}{\partial t} & =\frac{\beta}{t^{2}(\alpha+2 \beta)}>0, \quad \frac{\partial \phi^{*}}{\partial \beta}=\frac{-\alpha}{t(\alpha+2 \beta)^{2}}<0, \quad \frac{\partial \phi^{*}}{\partial \alpha}=\frac{\beta}{t(\alpha+2 \beta)^{2}}>0 \frac{\partial a_{i}^{*}}{\partial t}=\frac{-\beta(\alpha+\beta)}{(\beta-t(\alpha+2 \beta))^{2}}<0, \quad \frac{\partial a_{i}^{*}}{\partial \beta}=\frac{\alpha t}{(\alpha t+\beta(2 t-1))^{2}}>0, \\ \frac{\partial a_{i}^{*}}{\partial \alpha} & =\frac{-\beta t}{(\beta-t(\alpha+2 \beta))^{2}}<0\end{aligned}$

Appendix C. Numerical examples

$t=\{0.4,0.6\} ; \alpha=\{0.5,0.7\} ; \beta=\{0.3,0.5\} ; Y_{i}=\{10,20\}$

\begin{tabular}{|c|c|c|c|c|}
\hline \multicolumn{5}{|c|}{ Parameter values } \\
\hline $\mathbf{t}$ & 0.4 & 0.6 & 0.4 & 0.6 \\
\hline$\alpha$ & 0.7 & 0.7 & 0.5 & 0.5 \\
\hline$\beta$ & 0.3 & 0.3 & 0.5 & 0.5 \\
\hline$Y_{1}$ & 20 & 20 & 20 & 20 \\
\hline $\mathbf{Y}_{2}$ & 10 & 10 & 10 & 10 \\
\hline \multicolumn{5}{|l|}{ Variables } \\
\hline$\phi^{*}$ & 0.42 & 0.62 & 0.17 & 0.44 \\
\hline $\mathbf{a}_{\mathbf{i}}^{*}$ & 1.36 & 0.63 & 5.00 & 1.25 \\
\hline Effective $t$ & 0.55 & 0.38 & 2.00 & 0.75 \\
\hline $\mathrm{C}_{1}$ & 10.77 & 10.77 & 6.67 & 6.67 \\
\hline $\mathrm{C}_{2}$ & 5.38 & 5.38 & 3.33 & 3.33 \\
\hline $\mathbf{G L}_{1}$ & 4.62 & 4.62 & 6.67 & 6.67 \\
\hline $\mathbf{G L}_{2}$ & 2.31 & 2.31 & 3.33 & 3.33 \\
\hline $\mathbf{U}_{1}^{\mathrm{LG}}$ & 2.70 & 2.70 & 3.05 & 3.05 \\
\hline $\mathbf{U}_{2}^{\mathrm{LG}}$ & 2.01 & 2.01 & 2.36 & 2.36 \\
\hline Welfare & 4.71 & 4.71 & 5.40 & 5.40 \\
\hline Tax Revenue & 20.77 & 20.77 & 30.00 & 30.00 \\
\hline $\mathbf{Y}_{1}$ & 22.31 & 22.31 & 23.33 & 23.33 \\
\hline $\mathbf{Y}_{2}$ & 14.62 & 14.62 & 16.67 & 16.67 \\
\hline YDist(post) & 1.53 & 1.53 & 1.40 & 1.40 \\
\hline
\end{tabular}

\section{Appendix D. Simulations}

$\left(\alpha, \beta, t \in[0.1,1] ; x \in[1,10]\right.$; and $y_{2}=x y_{1}$ where the simulations pick the numbers from these ranges with 0.1 point intervals except for $x$. The incremental change for $x$ is 1 unit.). 
Appendix E. Numerical examples with spillover effects $\left(s_{\boldsymbol{i}}\right)$

$t=\{0.4\} ; \alpha=\{0.5,0.7\} ; \beta=\{0.3,0.5\} ; Y_{i}=\{10,20\}$

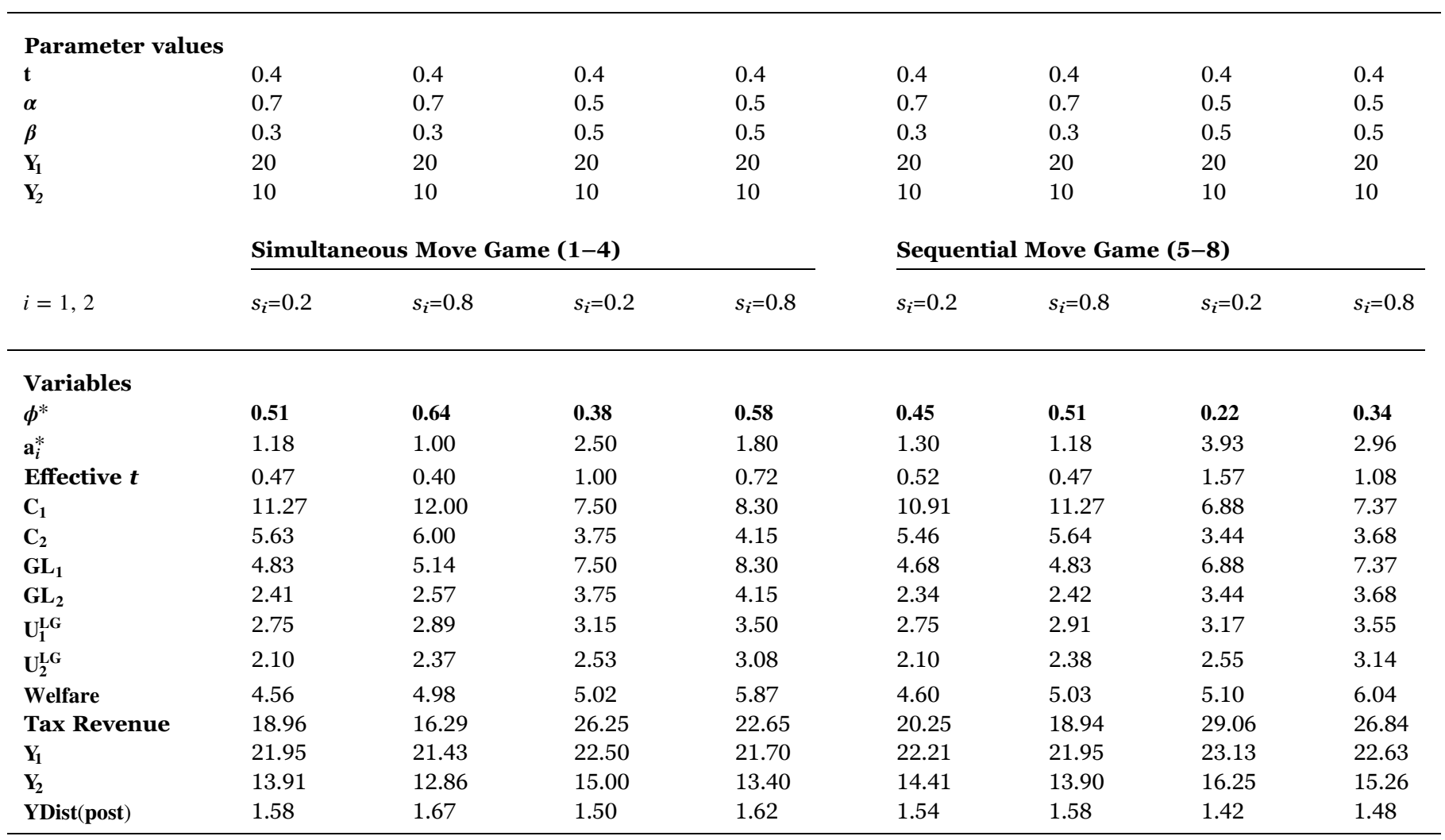

\section{Appendix F. Supplementary data}

Supplementary data associated with this article can be found in the online version at http://dx.doi.org/10.1016/j.econmod.2016.12.008.

\section{References}

Adam, A., Delis, M.D., Kammas, P., 2014. Fiscal decentralization and public sector efficiency: evidence from OECD countries. Econ. Gov. 15, 17-49.

Akin, Z., Bulut-Cevik, Z.B., Neyapti, B., 2014. Does fiscal decentralization promote fiscal discipline? Emerg. Mark. Financ. Trade 52 (3), 690-705.

Alesina, A., Hausmann, R., Hommes, R., Stein, E., 1999. Budget institutions and fiscal performance in Latin America. J. Dev. Econ. 59 (2), 253-273.

Bellofatto, A.A., Besfamille, M., 2015. Regional State Capacity and the Optimal Degree of Fiscal Decentralization. Documentos de Trabajo from Instituto de Economia. Pontificia Universidad Catlica de Chile. No. 460.

Besley, T., Coate, S., 2003. Central versus local provision of public goods: a political economy analysis. J. Public Econ. 87 (12), 2611-2637.

Boadway, R., Shah, A., 2009. Fiscal Federalism: Principles and Practice of Multiorder Governance. Cambridge University Press, New York.

Burki, S., Perry, G., Dillinger, W., 1999. Beyond the Center: Decentralizing the State. World Bank Latin America and Caribbean Studies. World Bank, Washington, DC.

Cremer, J., Palfrey, T.R., 1996. In or out?: centralization by majority voting. Eur. Econ. Rev. 40 (1), 43-60.

Crivelli, E., Staal, K., 2013. Size, spillovers and soft budget constraints. Int. Tax. Public Financ. 20 (2), 338-356.

Daughety, A.F. (ed.), 1989. Introduction to Cournot Oligopoly. Characterization and Applications, Cambridge University Press, Cambridge.

De Mello, L., Barenstein, M., 2001. "Fiscal Decentralization and Governance: A CrossCountry Analysis.” IMF Working Paper No. 01/71, International Monetary Fund, Washington D.C

Diamond, L., 1999. Developing Democracy: Toward Consolidation. John Hopkins University Press, Baltimore.

Fisman, R., Gatti, R., 2000. Decentralization and Corruption: Evidence Across Countries. World Bank Policy Research (Working Paper No. 2290). World Bank, Washington, DC.

Gradstein, M., 2016. Government decentralization as a committment in non- democracies, J. Comp, Econ., (forthcoming).

Hatfield, J.W., 2015. Federalism, taxation, and economic growth. J. Urban Econ. 87, $114-125$.

Janeba, E., Wilson, J.D., 2011. Optimal fiscal federalism in the presence of tax competition. J. Public Econ. 95, 1302-1311.

Koethenbuerger, M., 2008. Revisiting the "decentralization theorem" - on the role of externalities. J. Urban Econ. 64 (1), 116-122.

Lockwood, B., 2002. Distributive politics and the costs of centralization. Rev. Econ. Stud. 69, 313-337.

Mah, Jai S., 2013. Globalization, decentralization and income inequality: the case of China. Econ. Model. 31, 653-658.

Neyapti, B., 2010. Fiscal decentralization and deficits: international evidence. Eur. J. Political Econ. 26 (2), 155-166.

Neyapti, B., 2013. Fiscal decentralization, fiscal rules and fiscal discipline. Econ. Lett. 121 (3), 528-532.

Neyapti, B., Bulut-Cevik, Z.B., 2014. Fiscal efficiency, redistribution and welfare. Econ. Model. 41, 375-382.

Oates, W., 1972. Fiscal Federalism. Harcourt Brace Jovanowich, New York.

Oates, W., 1999. An essay on fiscal federalism. J. Econ. Lit. 37 (3), 1120-1149.

Oates, W., 1998. On the Welfare Gains from Fiscal Decentralization. Univ. of Maryland, Dept. of Economics WP 98-05.

Prud'homme, R., 1995. The dangers of decentralization. World Bank Res. Obs. 10, 201-220.

Qichun, H., 2014. Does fiscal decentralization promote the inflow of FDI in China? Econ. Model. 43, 271-361.

Rodden, J., 2002. The dilemma of fiscal federalism: grants and fiscal performance around the world. Am. J. Political Sci. 46 (3), 670-687.

Sanguinetti, P., Tomassi, M., 2004. Intergovernmental transfers and fiscal behaviour insurance versus aggregate discipline. J. Int. Econ. 62 (1), 149-170.

Sorens, J., 2014. Fiscal federalism, jurisdictional competition, and the size of government. Const. Political Econ. 25 (4), 354-375.

Stein, E., 1998. Fiscal Decentralization and Government Size in Latin America. In: Fukasaku, Kiichiro, Hausmann, Ricardo, (eds.), Democracy, Decentralisation and 
Deficits in Latin America, Inter-American Development Bank and OECD, Washington, D.C.

Stöwhase, S., Traxler, C., 2005. Tax evasion and auditing in a federal economy. Int. Tax. Public Financ. 12, 515-531.

Tanzi, V., 1994. Corruption, Government Activities, and Markets. IMF Working Paper 94/99. International Monetary Fund, Washington, DC.

Tanzi, V., 2000. On Fiscal Federalism: Issues to Worry About. Conference notes: Conference on Fiscal Decentralization, IMF, Fiscal Affairs Department, Washington DC.
Thiessen, U, 2003. Fiscal decentralization and growth in high-income OECD countries. Fisc. Stud. 24 (3), 237-274.

Tiebout, C., 1956. A pure theory of local public expenditures. J. Political Econ. 64 (5), 416-424.

Wang, Y., 2013. Fiscal decentralization, endogenous policies, and foreign direct investment: theory and evidence from China and India. J. Dev. Econ. 103, 107-123. Zhang, T., Zou, H., 1998. Fiscal decentralization, public spending, and economic growth in China. J. Public Econ. 67 (2), 221-240. 